\title{
Erratum to: Revisiting the Mesosome as a Novel Site of Hydrogen Peroxide Accumulation in Escherichia coli
}

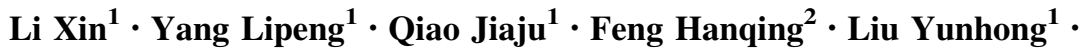
Zhang Min $^{1} \cdot$ Zhang Yuxian $^{1} \cdot$ Li Hongyu ${ }^{3}$

Published online: 23 January 2016

(c) Springer Science+Business Media New York 2016

Erratum to: Curr Microbiol (2014) 69:549-553

DOI 10.1007/s00284-014-0617-5

The original version of this article unfortunately contained a mistake. The affiliations of the authors were incorrect. The correct affiliations of authors are given in this erratum.

The online version of the original article can be found under doi:10.1007/s00284-014-0617-5.

Li Xin

lixinpxy@hotmail.com

1 College of Food and Bioengineering, Henan University of Science and Technology, Luoyang, China

2 College of Life Science, Northwest Normal University, Lanzhou, China

3 Institute of Microbiology, School of Life Sciences, Lanzhou University, Lanzhou, China 